\title{
Whom are we serving? An exploration of student demographics in a large engineering design projects ecosystem
}

\section{Prof. David A. Copp, University of California, Irvine}

David A. Copp received the B.S. degree in mechanical engineering from the University of Arizona and the M.S. and Ph.D. degrees in mechanical engineering from the University of California, Santa Barbara. He is currently an Assistant Professor of Teaching at the University of California, Irvine in the Department of Mechanical and Aerospace Engineering. Prior to joining UCI, he was a Senior Member of the Technical Staff at Sandia National Laboratories and an adjunct faculty member in Electrical and Computer Engineering at the University of New Mexico. His broad research interests include engineering education, as well as control and optimization of nonlinear and hybrid systems with applications to power and energy systems, multi-agent systems, robotics, and biomedicine. He is a recipient of UCSB's Center for Control, Dynamical Systems, and Computation Best PhD Thesis award.

\section{Ms. Alejandra Hormaza Mejia, University of California, Irvine}

Alejandra Hormaza Mejia is a PhD student in the department of mechanical and aerospace engineering at the University of California, Irvine. She received her B.S. in chemical engineering and M.S. in mechanical and aerospace engineering from the University of California, Irvine. Her research interests include renewable energy systems, renewable fuels, and equity and diversity in engineering education. She aspires to be an engineering professor in the future!

\section{Dr. Mark E Walter, University of California, Irvine}

Dr. Walter received his PhD in Applied Mechanics from Caltech. He spent a year as a Fulbright Postdoctoral Fellow doing materials science research at the Universitaet Karlsruhe. He joined the Ohio State University in January of 1997 and spent 17 years there running a research group, teaching mechanics and design classes, and advising two US Department of Energy solar decathlon teams. Dr. Walter's research was focused on understanding deformation and failure mechanisms at the micro-scale. In 1998 he received a NSF CAREER award to study thermal barrier coatings and was later active in studying durability of solid oxide fuel cell materials. After one year at the Fraunhofer Institute for Building Physics in Holzkirchen, Germany, in July of 2015, Dr. Walter joined the Department of Mechanical and Aerospace Engineering at the University of California, Irvine. At UCI Dr. Walter teaches regular MAE classes and helps to manage the senior projects program.

\section{Prof. Natascha Trellinger Buswell, University of California, Irvine}

Natascha Trellinger Buswell is an assistant professor of teaching in the department of mechanical and aerospace engineering at the University of California, Irvine. She earned her B.S. in aerospace engineering at Syracuse University and her Ph.D. in engineering education in the School of Engineering Education at Purdue University. She is particularly interested in teaching conceptions and methods and graduate level engineering education. 


\title{
Whom are we serving? An exploration of student demographics in a large engineering design projects ecosystem
}

\begin{abstract}
Project-based learning is a popular way for students to gain hands-on experience in engineering curriculums. Curriculum in the Department of Mechanical and Aerospace Engineering at the University of California, Irvine, allows students to participate in a variety of engineering design projects as early as the second quarter of their freshman year through their senior year. The projects ecosystem typically serves around 400 students, with the majority in mechanical engineering. These projects are largely student organized and run with the support of faculty advisors, and the number of students on each project varies from three students to over 100. With so much variability in the projects, we aim to better understand the differences in student experiences in our projects ecosystem. In particular, we comparatively study the experiences of low income, first generation, transfer, female, and underrepresented minority students. We similarly study the experiences of students on teams that have the goal of participating in a national or international competition versus those of students on non-competition teams. Using survey data from students in the project ecosystem, paired with institutional data on student demographics, we conduct an exploratory analysis to understand whom our projects ecosystem is serving.
\end{abstract}

\section{Introduction}

Project-based learning is often used in engineering classes to allow students to practice collaboration, communication, and teamwork. These skills are considered essential professional skills in the field of engineering and are often emphasized in engineering education curriculums [1]. At the University of California, Irvine, (UCI) students in the Department of Mechanical and Aerospace Engineering (MAE) are required to take 3 units of MAE Senior Design projects for graduation. Students may enroll in more units, 8 of which can be used for technical elective credit. Additionally, non-senior students may also enroll in the projects (with a separate course number) and are often motivated to participate due to the benefits of project involvement for potential job opportunities. The projects ecosystem at UCI serves around 450 students each quarter with three MAE faculty overseeing the entire project ecosystem and a faculty advisor for each project. Each project is student-led with students initiating, recruiting, forming, budgeting, and managing their own teams [2]. Although there are required courses within the MAE projects ecosystem, there is also an extracurricular "feel" to the projects, largely driven by students" intrinsic motivation in the subject and students' extrinsic motivation to "show off" their project to 
peers, to succeed in engineering design competitions related to their project, and gain experience to demonstrate their competencies in job applications and interviews.

Anecdotally, many MAE students have found the high level of student engagement, involvement, and leadership with each of the projects to be an appealing aspect of the unique MAE design project ecosystem. However, because the projects are student-led and student-managed, issues of diversity and inclusiveness are of concern. UCI is a Hispanic and Asian American and Native American Pacific Islander-serving institution (HSI and AANAPISI) with a diverse undergraduate student population; 32\% of the students are Asian and 24\% are Hispanic [3]. Additionally, 38\% of beginning undergraduates were awarded a Pell Grant in the 2017-2018 school year [4]. In recent years, $50 \%$ of bachelor's degrees have been awarded to first-generation college students [5]. MAE has a diverse student population with the following demographics: $17 \%$ are female, $26 \%$ are transfer, $43 \%$ are first-generation, and $30 \%$ are from low-income backgrounds. In this paper, we explore the diversity component of the MAE design project ecosystem. Particularly, we are interested in understanding the experience of low income, first generation, transfer, underrepresented minority, and female students.

\section{Literature Review}

While the value of experimental design projects has been emphasized in engineering curriculums, participation of underrepresented students in engineering competition teams is often low when compared to the engineering enrollment in the schools $[6,7]$. Much of the literature about the experience of underrepresented groups in engineering team projects has assessed several challenges that may prevent students from engaging and participating in team activities. Prior research has attributed the low participation of underrepresented students to recruitment strategies and the retention of students [6]. In many engineering competition teams, the teams are student-selected, which leads to homophily (the tendency for people to have (non-negative) ties with people who are similar to themselves in socially significant ways) because students are likely to recruit friends or classmates in their social network (e.g., see [1, 6-8]. For example, a study that examined the culture of engineering competition teams found that half of the students recruited to the engineering competition teams were recruited by peers and friends [6]. This may present a barrier for students who join outside of the social/peer network to be properly integrated with the team. In addition to the challenges of recruiting students that belong to underrepresented groups, prior research has shown that integration of underrepresented students is an even more significant problem in engineering competition teams [7].

While teamwork may allow students to practice professional skills such as communication, leadership, emotional intelligence, and time management, it may also highlight challenges within the culture of engineering, especially pertaining to the experience of first generation, transfer, underrepresented minority, and female students. Although the rhetoric that emphasizes the importance of professional skills, technical skills in engineering are highly valued [1]. Since students' perceptions of diversity are based on previous experiences, gender and racial/ethnic biases may influence the dynamics of the team, inhibiting the learning and participation of underrepresented students in teams [7]. Female students often report that gender biases affect their teaming experiences, since women are often assigned roles related to organization and note-taking in disproportion to the technical roles [1]. Additionally, female and underrepresented 
minority students encounter problems in teamwork such as having their ideas ignored, not being recognized for their contributions, and having to work on projects that are not relevant to them, which often leads to a negative teaming experience and negative views of teamwork [1].

Research has shown that the addition of a diversity requirement in one category, such as gender, does not promote the inclusion of other diverse groups, such as students from underrepresented racial/ethnic groups [7]. When a diverse team functions with inclusive practices, the benefits of diversity can be achieved; such as when students feel comfortable raising new perspectives and challenging tradition. Prior research recommends "strategic planning and intentional implementation" to increase diversity of engineering teams and the integration of such teams [7]. For example, the authors of [1] strongly advise the instructors to form the teams and base their decisions on the characteristics of the individual students. Characteristics may include gender, experience level, students' schedules [1], race/ethnicity, major, and ability. It may also be beneficial for the instructors to assign and rotate team roles to prevent gender biases from perpetuating students' roles in teams and to facilitate inclusive teamwork [1]. Others suggest avoiding isolating minority students on teams during the first two years [9]. Additionally, to create a more inclusive student team environment, the authors of [10] recommend properly training students to develop the skills that are necessary to work with a diverse team. This would ultimately allow students to develop cognitive empathy to support each other [10]. The author of [11] describes team members need to feel "psychologically safe," or having "the shared belief among team members that the team is safe for interpersonal risk-taking." Furthermore, the author explains that "team psychological safety involves but goes beyond interpersonal trust; it describes a team climate characterized by interpersonal trust and mutual respect in which people are comfortable being themselves" [11].

Lastly, including more culturally relevant project opportunities may be beneficial to engage a broader group of engineering students [8]. Students with diverse backgrounds may be more excited and interested in projects that are familiar to them. This may also allow students to leverage their cultural knowledge and apply it to the projects. A study that assessed the impacts of curricular and co-curricular/ extracurricular project-based service-learning opportunities in various schools found that female and underrepresented minority students participate in service projects at significantly higher rates [12]. The results from the study indicate that project-based service learning effectively recruits underrepresented students in engineering [12].

It may be challenging to apply these recommendations from the literature to the current MAE project ecosystem since the nature of the design program encourages students to be influential decision makers in the recruitment, management, and design aspects of each project. This is especially true for 'competition teams' - project teams that have a goal of competing in a national or international competition. Additionally, since the MAE project ecosystem is comprised of a diverse student population, we are interested in examining the current state of the project ecosystem from a diversity lens in order to determine more equitable strategies to ensure inclusion and the participation of diverse students.

\section{Current State of the Projects Ecosystem}

MAE projects at UCI evolved several times since the first required projects courses were put in place in the early 80s. Some of the historical details can be found in [2]. The first projects served 
50-60 students per quarter and were student initiated and managed and tended to be large and ambitious. In the early 90s an accident forced projects "inside" onto 3'x8' tables, and over a couple of years, only industry-sponsored projects were offered. By the late 90s, students were again initiating and managing their own projects, and 3 units of Senior Projects became required for graduation. When students were able to use up to 8 more units of Senior Projects as technical electives, projects began to be more involved, year-long endeavors. Between 2013 and 2015 project enrollments went from 150 to 300 students. Non-seniors were then also allowed and encouraged to formally join projects through work-load-credit classes. The majority of projects had limited or no faculty-advisor involvement, and it became obvious that more structure was needed given both the large numbers of students and the fact that the project work was required for graduation.

The initial structure in the 2014-2015 academic year requested project-level documentation and participation in quarterly design reviews. By the 2017-2018 academic year, project-level documentation was required of all teams. In the 2018-2019 academic year each Senior Projects student was required to report on their project work in a weekly 10-person 50-minute check-in session and to submit scans of their notebooks to the newly formed MAE Projects coordination team. Grades for the individual work and team documentation were given by faculty advisors. The final iteration to the current academic year requires each Senior Projects student to be part of a team that submits a design report for a component, assembly, or system that is related to their project. The focus for these students is on engineering design process activities and not project management and fabrication. Check-in sessions are still required, and faculty project advisors receive feedback on student performance in check-ins. Team-level documentation is no longer collected, but participation in design reviews and maintaining a project page on the School's student projects website are required.

In the current academic year, there are about 30 projects with close to half of these projects being for national student competitions. Over two-thirds of the students involved in MAE projects are part of these competition teams, and some of these teams have 40+ students. In the Winter 2020 quarter, of the 450 students enrolled in MAE projects, 165 are enrolled in Senior Projects. The rest of the students are enrolled in the lower-division course and receive work-load credit. Faculty project advisers are being asked to play a more significant role in publishing a syllabus for their project, scoping design report materials, and assessing individual and team project work. For almost all of the MAE projects, students are doing all the project planning and execution. In many cases, students are also managing the teams, including who receives an add code, selecting team leads, and when applicable, which sub-team each member is on. Given the current state of the MAE Projects ecosystem and the issues raised in the Literature Review, we decided to take a closer look at student demographics as they related to diversity and teaming.

\section{Analysis of Demographics and Teaming Outcomes}

\section{Data Collection}

The data for this study consists of survey data and institutional data. The survey data that is examined in this paper are from the 2019 Winter Quarter. Students were asked a myriad of questions pertaining to their projects and experiences at the end of the quarter; however, in this 
paper, we focus on five questions that were asked about their teaming experiences. The questions are below, for which students had the following Likert scale response options: agree (1), tend to agree (2), tend to disagree (3), disagree (4):

1. I am clear on my team's goals.

2. I understand what is expected for the team requirements in this course (e.g. documentation, peer-review, progress reviews, design reviews, etc.).

3. I have personal ownership of my team's mission and goals.

4. My team has an open communication structure that allows all members to participate.

5. I feel that everyone's opinions and suggestions are considered on my team.

In order to study the demographic variability in survey responses, we worked with the UCI's Teaching Center to get demographic institutional data for the students in MAE Senior Projects starting in Fall 2017 through Spring 2019. All data was collected with approval from the University's Institutional Review Board.

\section{Student Participants}

To begin, the demographics for the students who participated in the MAE projects ecosystem over a three-year period are reported in Table 1. Some students participated in projects multiple times over this period, but each individual student is only counted once.

Table 1: Projects student demographic numbers for Fall 2017 - Spring 2019

\begin{tabular}{|c|c|c|}
\hline Group & Number of Students & Percentage of Total \\
\hline All & 879 & $100 \%$ \\
Low Income & 258 & $29 \%$ \\
First Generation & 385 & $44 \%$ \\
Transfer & 294 & $33 \%$ \\
Female & 154 & $18 \%$ \\
URM & 271 & $31 \%$ \\
None & 202 & $23 \%$ \\
Female \& Low Income & 53 & $6 \%$ \\
Female \& First Generation & 61 & $7 \%$ \\
Female \& Transfer & 40 & $5 \%$ \\
Female \& URM & 53 & $6 \%$ \\
\hline
\end{tabular}

Of the students who responded to the survey in Winter 2019 (Table 2), the percentage of students from each demographic group is similar to the overall percentages over those three years (Table 1), so the data from the quarter of interest (Winter 2019) for which we collected and analyzed survey data is representative of the project ecosystem at large.

Table 3 shows the demographic numbers for all students in MAE during Winter 2019. In this table, we see that the demographic groups are roughly the same as those who participate in the MAE projects ecosystem. One difference is in the number of URM students: at the institutional 
Table 2: Projects student demographic numbers for those surveyed Winter 2019

\begin{tabular}{|c|c|c|}
\hline Group & Number of Students & Percentage of Total \\
\hline All & 240 & $100 \%$ \\
Low Income & 83 & $35 \%$ \\
First Generation & 102 & $43 \%$ \\
Transfer & 82 & $34 \%$ \\
Female & 50 & $21 \%$ \\
URM & 70 & $29 \%$ \\
None & 54 & $23 \%$ \\
Female \& Low Income & 18 & $8 \%$ \\
Female \& First Generation & 17 & $7 \%$ \\
Female \& Transfer & 14 & $6 \%$ \\
Female \& URM & 19 & $8 \%$ \\
\hline
\end{tabular}

level URM status is given to students who identify as Black, Latino, American Indian, Pacific Islander, Chicano, or Pilipino. The URM calculation for engineering also includes Asian students, which is a large percentage of the engineering population. In our presentation of results, we use the institutional definition of URM.

Table 3: Student demographic numbers for the MAE department, Winter 2019

\begin{tabular}{|c|c|c|c|c|}
\hline Group & $\begin{array}{c}\text { Students } \\
\text { in Aerospace }\end{array}$ & $\begin{array}{c}\text { Percentage of } \\
\text { Total Aerospace }\end{array}$ & $\begin{array}{c}\text { Students } \\
\text { in Mechanical }\end{array}$ & $\begin{array}{c}\text { Percentage of } \\
\text { Total Mechanical }\end{array}$ \\
\hline All & 358 & $100 \%$ & 936 & $100 \%$ \\
Low Income & 113 & $32 \%$ & 276 & $29 \%$ \\
First Generation & 161 & $45 \%$ & 399 & $43 \%$ \\
Transfer & 70 & $20 \%$ & 267 & $29 \%$ \\
Female & 49 & $14 \%$ & 173 & $18 \%$ \\
URM $^{1}$ & 251 & $70 \%$ & 710 & $76 \%$ \\
\hline
\end{tabular}

\section{Research Questions}

This exploratory research project seeks to answer the following research questions:

1. To what extent do teaming experiences differ based on student demographic data in engineering design project teams?

2. To what extent do teaming experiences differ based on if the project team is a competition team?

In order to answer these questions, we employ the use of the Kruskal-Wallis Test to test the following Null hypotheses:

\footnotetext{
${ }^{1}$ In these data, URM status is given to students who identify as American Indian / Alaskan Native, Asian / Pacific Islander, Black (non-Hispanic), and Hispanic. This URM categorization differs from Tables 1 and 2 above.
} 
1. Null hypothesis: a student's teaming experience is independent of their demographics

2. Null hypothesis: a student's teaming experience is independent of their team status as a competition team.

\section{Data Analysis}

We perform hypothesis-testing of the data to determine if there are significant differences in the responses to the questions listed above from different groups of students. In particular, we group students by the following demographics: 'Low Income,' 'First Generation,' 'Transfer,' 'Female,' 'URM,' and 'None,' where 'None' is the category for all students who are not identified as at least one of the other demographics. We also include a group called 'Competition,' which includes students who are on project teams that have the goal of participating in a competition, such as AIAA's Design-Build-Fly competition. The competition teams tend to have more students and more organizational structure between sub-teams.

For hypothesis-testing, we employ Kruskal-Wallis tests and analyze the resulting p-values. The Kruskal-Wallis test is a nonparametric test that compares the medians of groups of data to determine if their samples come from the same population (or distribution). In these analyses, the null hypothesis is that the responses from different groups of students are from the same distribution. Therefore, if the p-value is small (e.g., less than 0.05), then the null hypothesis is rejected, and we say that there are statistically significant differences between the responses of students from different groups. We compare both specific groups to the remainder of the students surveyed, as well as specific demographics to the 'None' group. The p-values resulting from these tests are given in Tables 4 and 5.

Table 4: p-values from Kruskal-Wallis Test of data from particular groups compared to all other data (p-values $<0.059$ are marked in red and with an asterisk.)

\begin{tabular}{|c|c|c|c|c|c|}
\hline \multirow{2}{*}{ Group } & \multicolumn{5}{|c|}{ Survey Question } \\
\cline { 2 - 6 } & 1 & 2 & 3 & 4 & 5 \\
\hline Low Income & 0.606 & 0.161 & 0.956 & 0.149 & 0.857 \\
First Gen & 0.177 & 0.166 & 0.570 & 0.102 & 0.546 \\
Transfer & 0.337 & 0.451 & 0.753 & 0.897 & 0.794 \\
Female & 0.179 & 0.670 & 0.595 & 0.418 & 0.407 \\
URM & 0.941 & 0.490 & 0.831 & 0.607 & 0.643 \\
None & 0.604 & $0.0251 *$ & 0.713 & $0.0581 *$ & 0.436 \\
Competition & $0.0136 *$ & 0.288 & $0.0057 *$ & 0.757 & 0.448 \\
\hline
\end{tabular}

Figures 1 through 5 show the data corresponding to the significant p-values marked in red in Tables 4 and 5. For our Likert scale questions, 'Agree' corresponds to a score of 1, and 'Disagree' corresponds to 4. For all Figures 1-7, the median for each group is shown as a solid red line, and the mean is shown as a blue circle. The bottom and top edges of the box indicate the 25th and 75th percentiles, respectively, and the distance between edges denotes the interquartile range. The whiskers capture the remainder of the data points not considered to be outliers. The red pluses denote outliers, which are values more than 1.5 times the interquartile range away from the top or bottom of the box. 
Table 5: p-values from Kruskal-Wallis Test of data from particular demographic groups compared to data from the 'None' group ( $\mathrm{p}$-values $<0.054$ are marked in red and with an asterisk.)

\begin{tabular}{|c|c|c|c|c|c|}
\hline \multirow{2}{*}{ Group } & \multicolumn{5}{|c|}{ Survey Question } \\
\cline { 2 - 6 } & 1 & 2 & 3 & 4 & 5 \\
\hline Low Income & 0.784 & 0.175 & 0.736 & 0.279 & 0.546 \\
First Gen & 0.931 & 0.141 & 0.867 & 0.268 & 0.600 \\
Transfer & 0.893 & $0.0324 *$ & 0.671 & 0.120 & 0.454 \\
Female & 0.260 & $0.0532 *$ & 0.586 & 0.264 & 0.771 \\
URM & 0.684 & $0.035^{*}$ & 0.692 & 0.178 & 0.619 \\
\hline
\end{tabular}

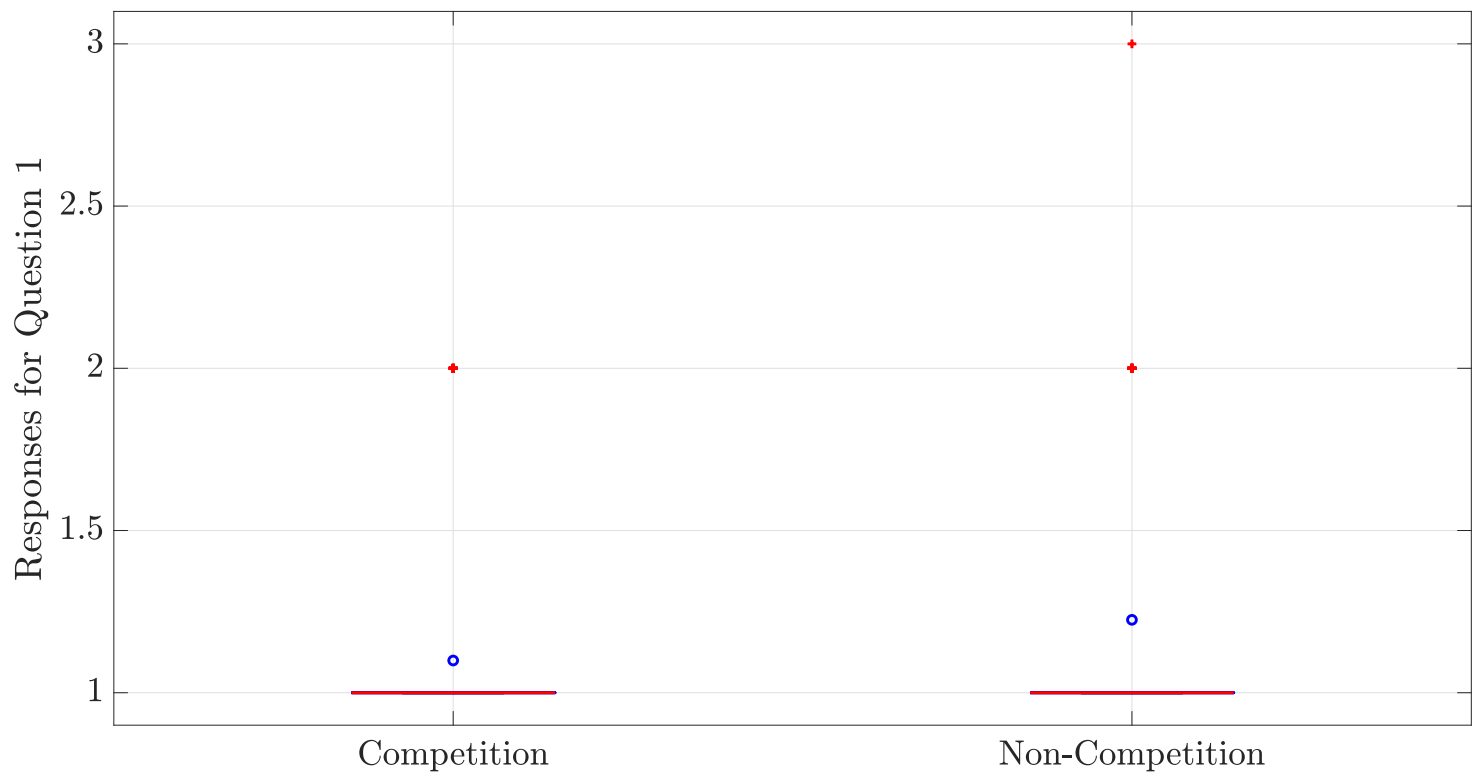

Figure 1: Statistics for responses of students in the 'Competition' group and all others to Survey Question 1.

While responses to Question 5 were not statistically significantly different from different groups, the mean response for students in the 'None' group was slightly larger than the mean response for all other groups, and the mean response for students in the 'Competition' group was slightly smaller than the mean response for all other groups. This is shown in Figure 6.

Finally, we were interested in seeing if students from our various demographic groups engaged in the MAE projects ecosystem at different frequencies. Specifically, we wanted to know how many times students repeated the course over three years. These statistics are presented in Figure 7.

\section{Discussion}

We will work to answer our research questions below, restated for convenience, by considering any differences in responses to the survey questions, also restated below. 


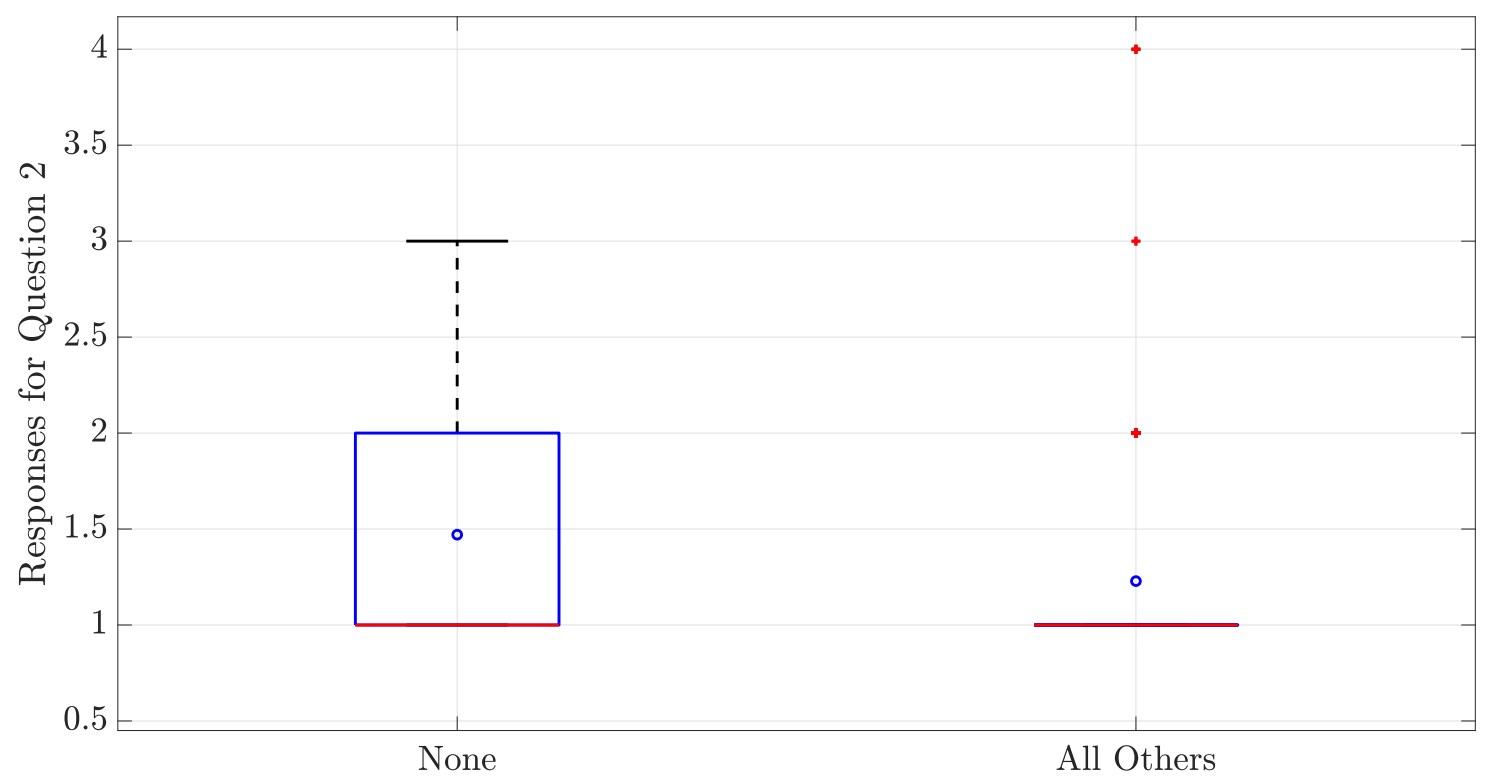

Figure 2: Statistics for responses of students in the 'None' group and all others to Survey Question 2.

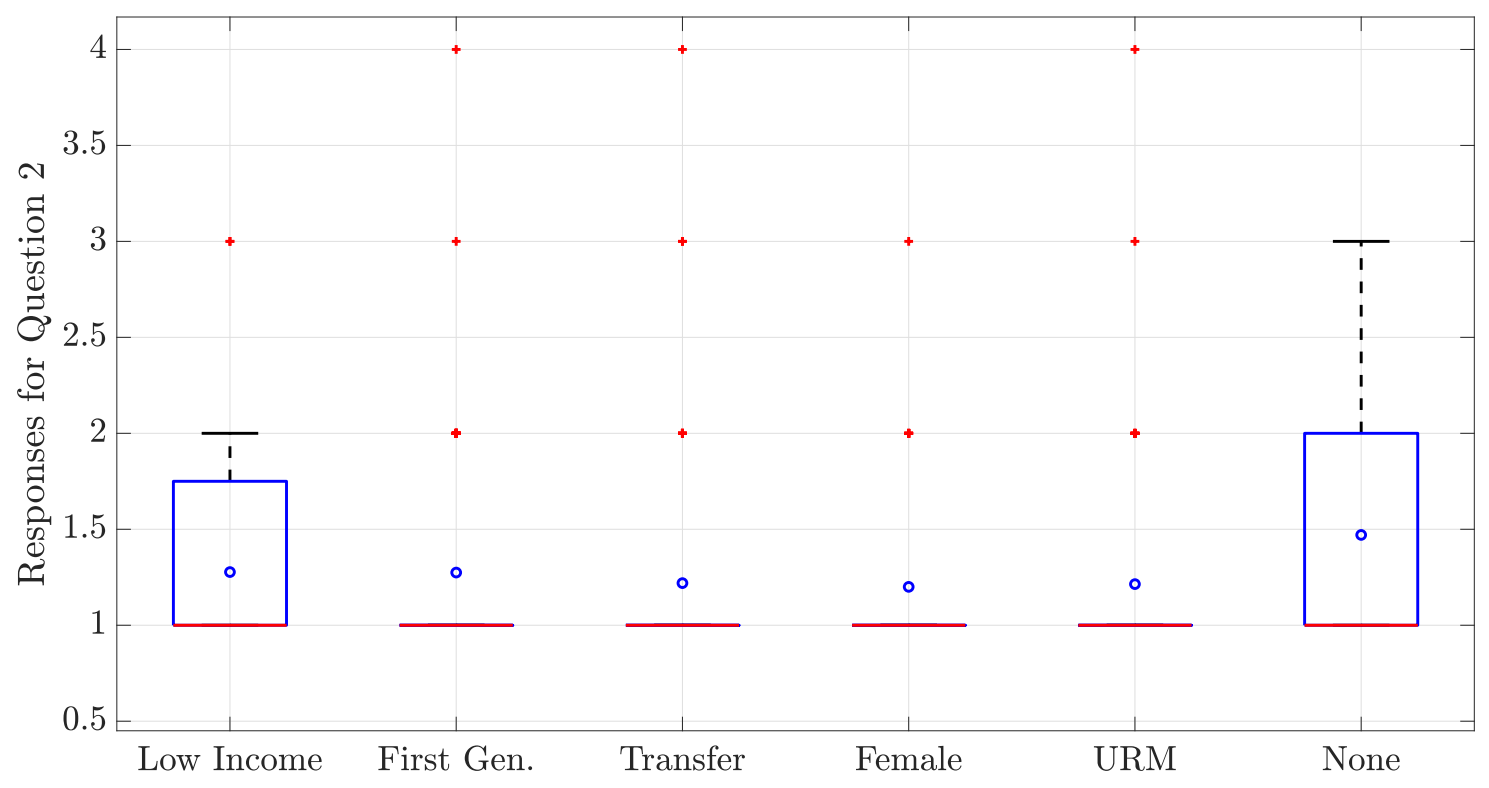

Figure 3: Statistics for responses of students in all the demographic groups to Survey Question 2.

\section{Research Questions (restated)}

1. To what extent do teaming experiences differ based on student demographic data in engineering design project teams?

2. To what extent do teaming experiences differ based on if the project team is a competition team? 


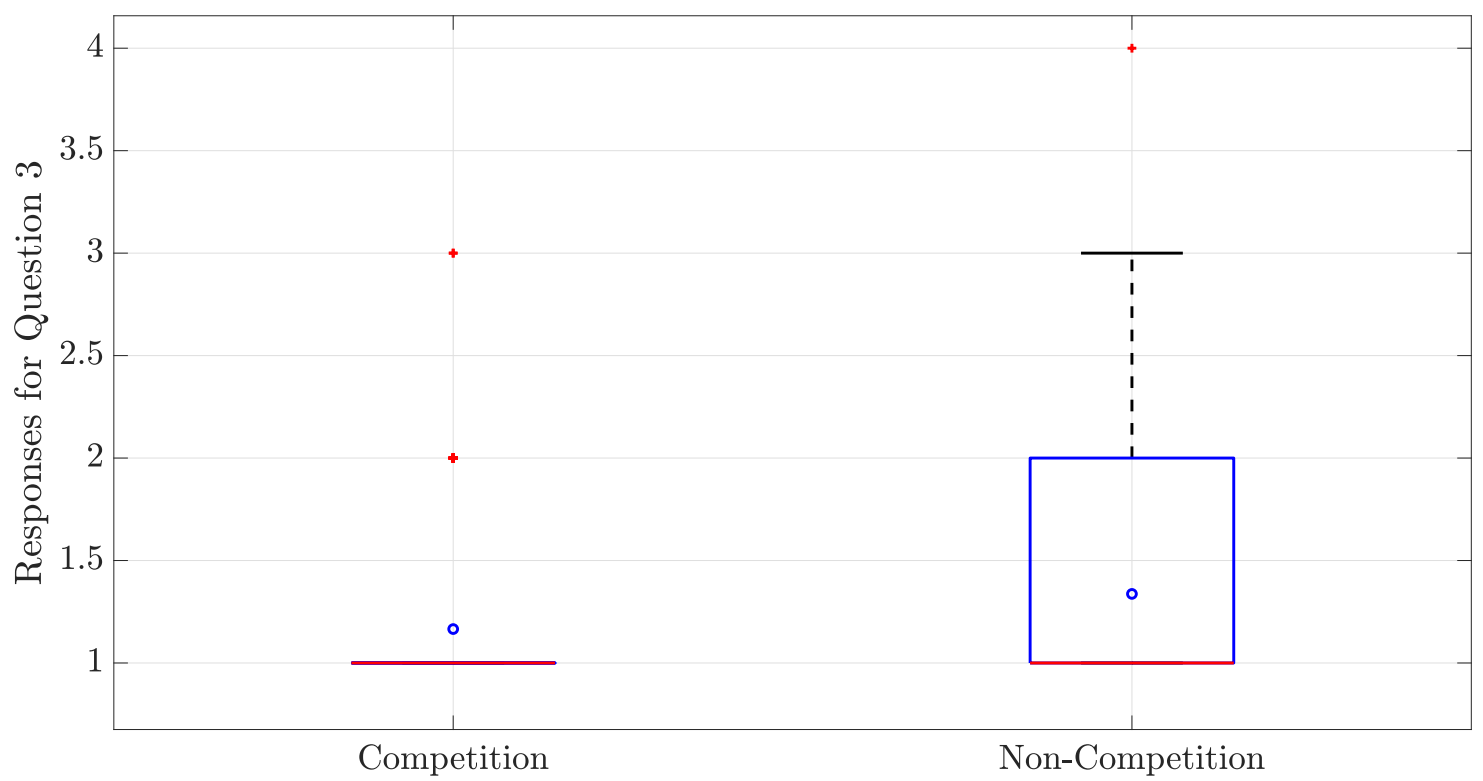

Figure 4: Statistics for responses of students in 'Competition' group and all others to Survey Question 3.

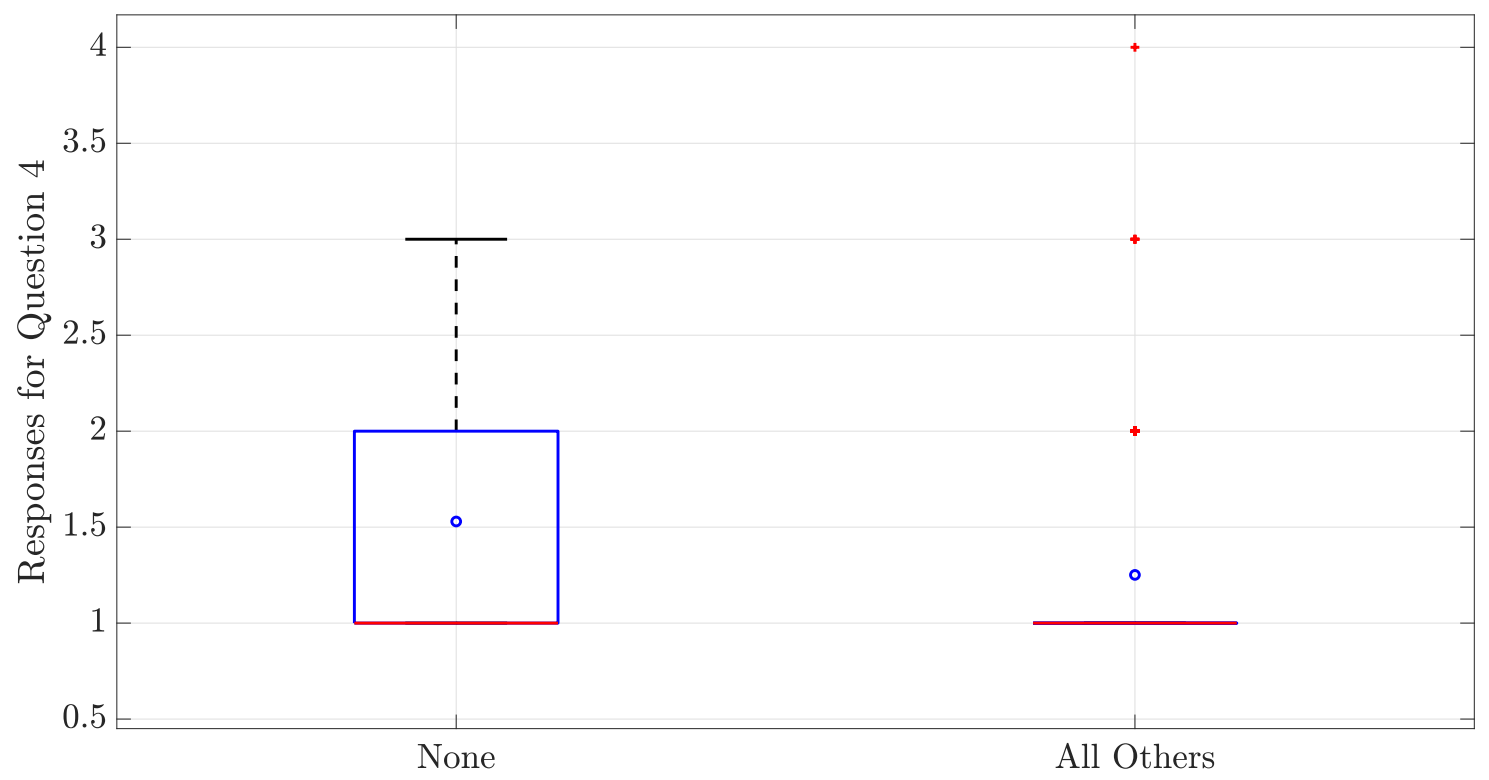

Figure 5: Statistics for responses of students in the 'None' group and all others to Survey Question 4.

Survey Questions (restated)

1. I am clear on my team's goals.

2. I understand what is expected for the team requirements in this course (e.g. documentation, peer-review, progress reviews, design reviews, etc.). 


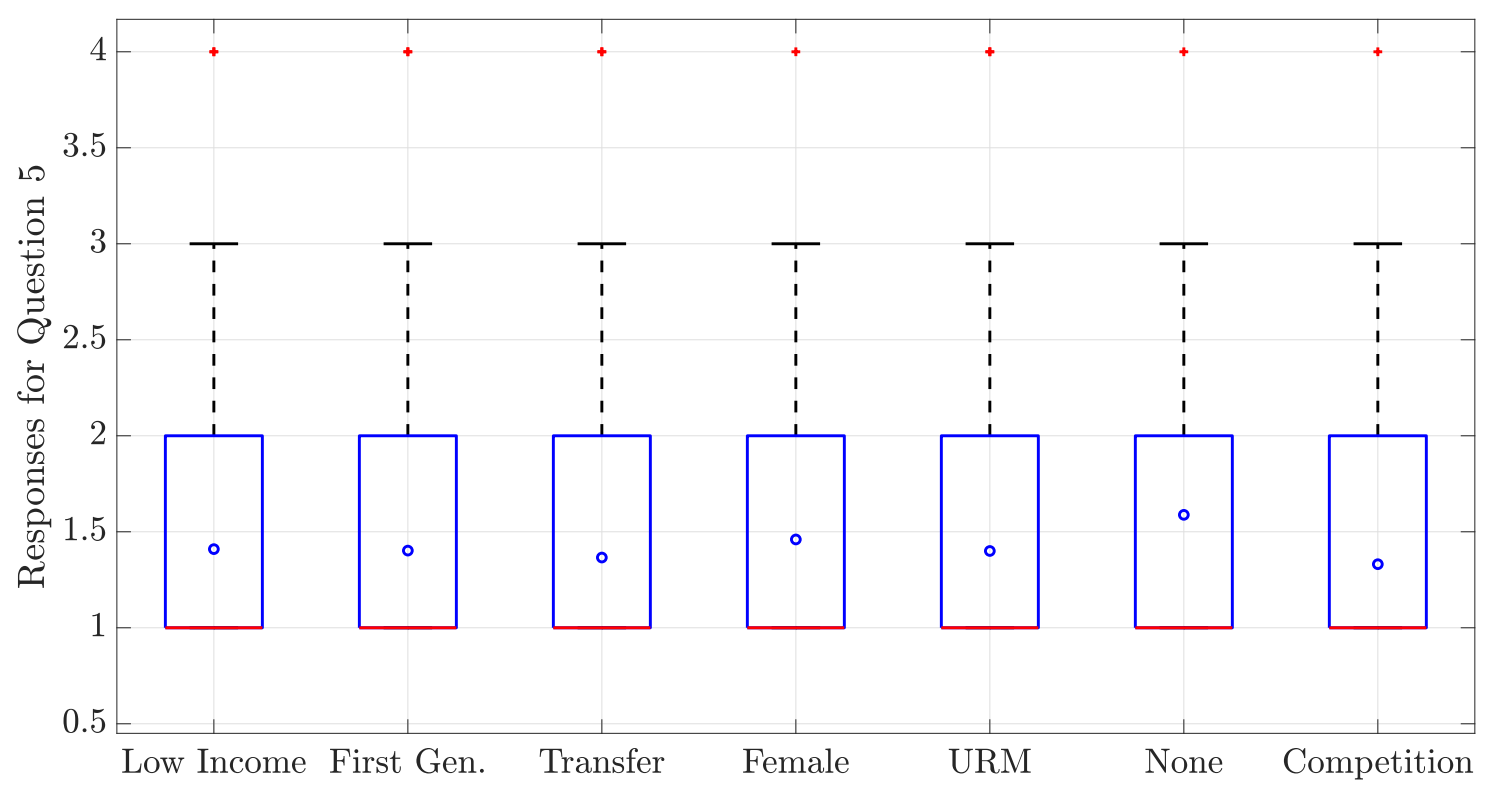

Figure 6: Statistics for responses of all student groups to Survey Question 5.

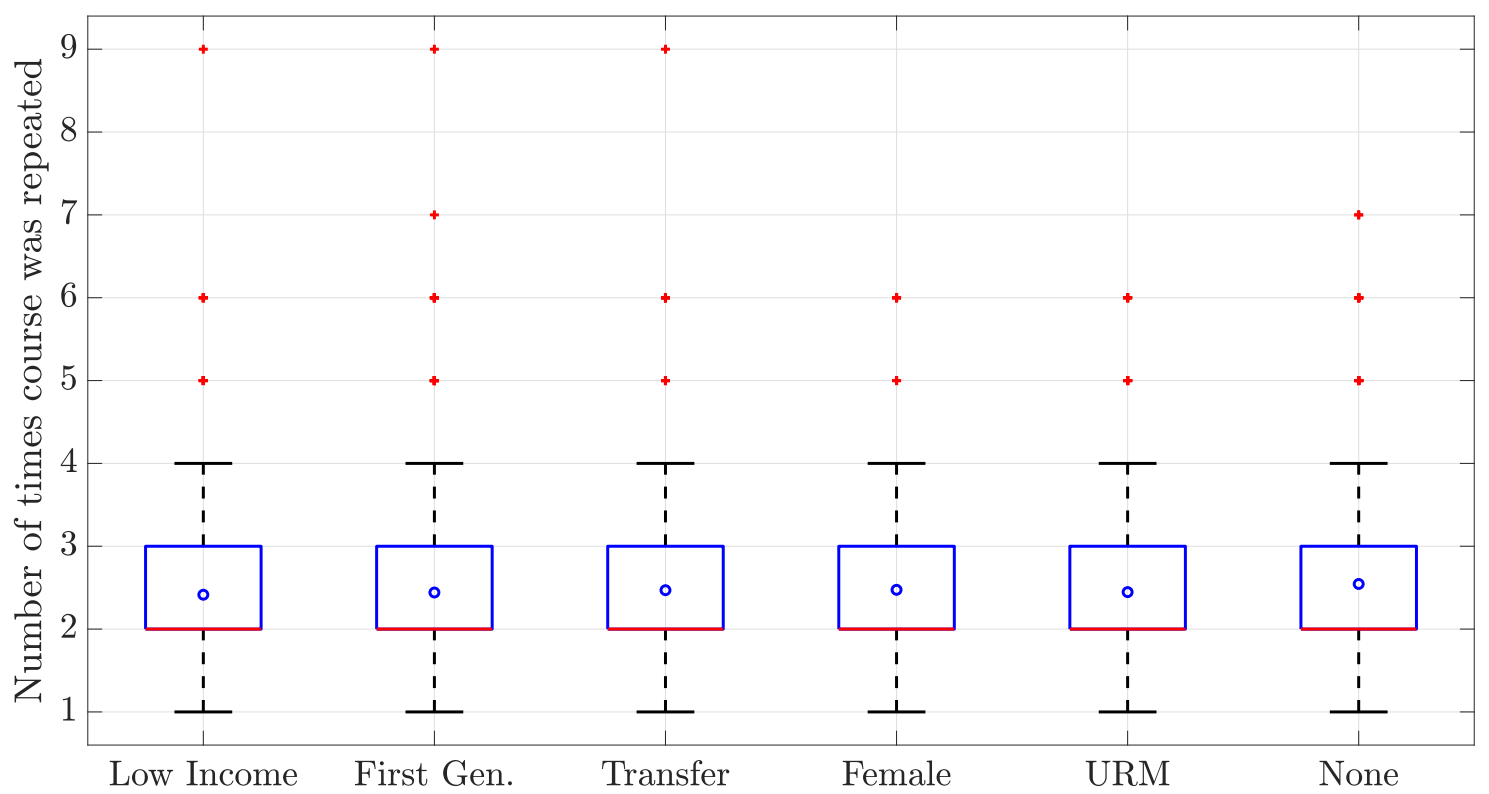

Figure 7: Statistics of how many times students in different demographic groups repeated the course over the three-year period.

3. I have personal ownership of my team's mission and goals.

4. My team has an open communication structure that allows all members to participate.

5. I feel that everyone's opinions and suggestions are considered on my team.

In response to Research Question 1 about student demographics, we found that for Survey Question 2 (I understand what is expected for the team requirements in this course), responses 
from students in the 'None' group had a larger distribution than all other students. In particular, we found that the distribution was significantly different from Transfer, Female, and URM responses - students from these demographics were more likely to respond 'Agree' and had a smaller distribution in their response. It is possible that students from these demographics have a different experience with course requirements, however, understanding their experiences in a deeper way is needed since this finding runs counter to what the literature says. The literature points us to expect that students from these demographics have a more difficult time integrating into teams [7]. The authors of [1] also describe that female students often report that gender biases affect their teaming experiences, since women frequently do more administrative tasks rather than technical tasks. However, it could be that students doing more administrative tasks report more familiarity with team requirements. These results may also broadly indicate how comfortable students in different groups feel responding with 'Tend to Agree' or 'Tend to Disagree.'

Similarly, for Survey Question 4 (My team has an open communication structure that allows all members to participate) the students who are not identified as a particular demographic group again have a larger distribution of responses.

Additionally, we checked to see if students from different demographic groups were engaging in the project ecosystem with different frequencies. We found no significant differences between how many times students in different demographic groups repeated the course (either Senior Projects or the accompanying lower division course). For all groups, the median number of quarters in which students participated in the projects ecosystem was two quarters. If there is any difference, on average, low income students repeated it the least, and students not in one of the demographic groups repeated it the most of any group.

From these data and results, we see that the project experiences are not significantly different for a particular demographic group, aside from one question demonstrating that Transfer, Female, and URM students statistically significantly differ in their reported understanding about what is expected for the team requirements in the course (they reported higher agreement with the statement that they understand what is expected for the team requirements). The authors of [9] explain that having minority students isolated on teams may lead to these students not being fully engaged and passively participating on their teams. These findings suggest that understanding the teaming experience for students of varying class-level (e.g. first-years vs seniors) is an important variable to consider but is one that we did not include in our analysis thus far.

In general, the lack of differences in responses could be because of the inherent diversity in our program. In other words, perhaps the lack of a "majority" demographic leads to less distinct demographic differences. These results do not say that everyone's experience is the same, but one demographic group's responses are not distinct from all other responses. Therefore, we conclude that demographic data are not independent predictors for these survey responses.

In response to Research Question 2 about the teaming experiences of students on competition teams, we found that for Survey Question 1 (I am clear on my team's goals), students on competition teams were more likely to respond 'Agree' than non-competition students. As we stated earlier, competition teams often receive specific requirements from the organization that runs the competition (e.g., AIAA), making this result expected. For Survey Question 3 (I have personal ownership of my team's mission and goals), students on competition teams were again 
more likely to respond 'Agree' than con-competition students. This result is also consistent with expectations; since competition teams likely have a clear mission and goals, students who join these teams may have greater personal interest or motivation in the project, thereby allowing them to feel more personal ownership. The literature points to concerns with competition teams having more challenges recruiting and including diverse students [6]. Our projects do not suffer from a lack of diversity, but further analysis is required to better understand the effects of student-run recruitment in our projects ecosystem.

While much research points to the need to be intentional in creating teams in order to ensure inclusivity of diverse students on engineering teams $[1,7,9]$, from the data we collected, we do not see any significant differences in the experiences of students from underrepresented backgrounds and those of students in majority groups. However, we acknowledge that our study contained numerous limitations. Mainly, our Survey Questions were general and are not validated measures. However, in this initial exploratory study, we were able to confirm that the experiences of our students are largely the same, independent of their demographic characteristics and if their team was a competition team or not.

\section{Summary and Future Work}

In this paper, we aimed to better understand the experiences of the students in the MAE projects ecosystem. In particular, we wanted to conduct an exploratory study to understand if students from different demographic groups experience teaming differently, and if being on a competition team made any difference. Using hypothesis testing with the Kruskal-Wallis Test, we found that there were a few instances where student responses differed based on demographics or competition status, however, overall, the experiences seem largely the same.

Our next steps include employing more nuanced survey questions and potentially using validated survey measures (including questions specifically related to psychological safety [11]) to examine non-cognitive attitudes about students' experiences in our MAE projects ecosystem. We would also like to explore in more depth how students report on their selection process for which project team to join, if the role students take within their projects affects their experiences, and if class-level (i.e. first-years vs seniors) affects their experiences. In addition, studying the MAE projects ecosystem from the faculty advisors' perspectives could also provide additional insight into whom we are serving through this educational experience.

\section{References}

[1] K. Beddoes and G. Panther, "Gender and teamwork: an analysis of professors' perspectives and practices," European Journal of Engineering Education, vol. 43, no. 3, pp. 330-343, 2018.

[2] N. T. Buswell and M. E. Walter, "Designing senior design for student-led projects with large enrollments," in 2019 ASEE Annual Conference \& Exposition, 2019.

[3] "University of California-Irvine: \#1 in MONEY's 2019-20 Best Colleges Ranking," 
https://money.com/best-colleges/profile/university-of-california-irvine/, accessed 17 Apr. 2020.

[4] "College Navigator - University of California-Irvine," https://nces.ed.gov/collegenavigator/ ?q=university+of+california+irvine \&s=CA\&id=110653\#enrolmt, accessed 17 Apr. 2020.

[5] "First-generation students make up half of UCI's class of 2018," https: //news.uci.edu/2018/06/04/first-generation-students-make-up-half-of-ucis-class-of-2018/, accessed 17 Apr. 2020.

[6] R. Pan, R. Shehab, C. Foor, D. Trytten, and S. Walden, "Building diversity in engineering competition teams by modeling industry best-practice," in 2015 ASEE Annual Conference \& Exposition, 2015.

[7] D. A. Trytten, R. Browning, C. Thomas, C. Foor, R. Shehab, S. Walden, and C. Pan, "Engineering competition team recruitment and integration strategies impact on team diversity," in 2016 IEEE Frontiers in Education Conference (FIE). IEEE, 2016, pp. 1-9.

[8] S. E. Walden, C. E. Foor, R. Pan, R. L. Shehab, and D. A. Trytten, "Advisor perspectives on diversity in student design competition teams," in 2016 ASEE Annual Conference \& Exposition, 2016.

[9] B. Oakley, R. M. Felder, R. Brent, and I. Elhajj, “Turning student groups into effective teams," Journal of student centered learning, vol. 2, no. 1, pp. 9-34, 2004.

[10] R. L. Norris and Z. Siddique, "Initiatives for creating a more inclusive engineering environment with limited resources and minimum disruption," in 2016 ASEE Annual Conference \& Exposition, 2016.

[11] A. Edmondson, "Psychological safety and learning behavior in work teams," Administrative science quarterly, vol. 44, no. 2, pp. 350-383, 1999.

[12] A. Bielefeldt, K. Paterson, and C. Swan, "Measuring the impacts of project-based service learning," in 2009 ASEE Annual Conference \& Exposition, 2009. 